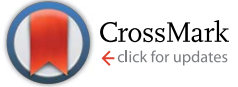

Cite this: J. Mater. Chem. A, 2015, 3, 3480

Received 7th December 2014

Accepted 15th December 2014

DOI: $10.1039 / \mathrm{c} 4 \mathrm{ta0} 6715 \mathrm{k}$

www.rsc.org/MaterialsA

\section{A high-rate aqueous symmetric pseudocapacitor based on highly graphitized onion-like carbon/ birnessite-type manganese oxide nanohybrids $\uparrow$}

\author{
Katlego Makgopa, ${ }^{a}$ Paul M. Ejikeme, ${ }^{a}$ Charl J. Jafta, ${ }^{\text {b }}$ Kumar Raju, ${ }^{\text {b }}$ Marco Zeiger, ${ }^{\text {cd }}$ \\ Volker Presser*cd and Kenneth I. Ozoemena*ab
}

\section{Introduction}

Supercapacitors are advanced systems for electrochemical energy storage. ${ }^{1,2}$ Two different types of supercapacitors can be differentiated: (a) electrical double-layer capacitors (EDLCs) that only rely on charge storage via ion electrosorption in an electrical double-layer, and (b) pseudocapacitors that utilize fast (surface) redox reactions..$^{3-6}$ Over the last years, supercapacitors have attracted tremendous attention due to their excellent properties such as high power density, long cycle ability, high efficiency, and relying on abundantly available carbon materials. ${ }^{7,8}$ Considering energy and power performance, supercapacitors play a key role as intermediates between batteries and electrolytic capacitors ${ }^{9}$ and find widespread applications for fast charge-discharge and uninterrupted power supply applications as well as in combination with batteries in hybrid systems. ${ }^{10}$ There have been extensive studies of varieties of carbon materials for supercapacitor electrodes because of their large specific surface area (SSA), high conductivity, facile availability, and chemical stability. ${ }^{5,11}$ Some of

\footnotetext{
${ }^{a}$ Department of Chemistry, University of Pretoria, Pretoria 0002, South Africa. E-mail: kozoemena@csir.co.za; Fax: +27-128412135; Tel: +27-128413664

${ }^{b}$ Energy Materials, Materials Science and Manufacturing, Council for Scientific \& Industrial Research (CSIR), Pretoria 0001, South Africa

'INM-Leibniz Institute for New Materials, 66123 Saarbrücken, Germany. E-mail: volker.presser@inm-gmbh.de; Fax: +49-6819300223; Tel: +49-6819300177

${ }^{d}$ Saarland University, 66123 Saarbrücken, Germany

$\dagger$ Electronic supplementary information (ESI) available. See DOI: 10.1039/c4ta06715k
}

the best performing carbon materials include activated carbon, ${ }^{\mathbf{1 2}}$ carbon nanotubes (CNTs), ${ }^{13}$ graphene, ${ }^{\mathbf{1 4 , 1 5}}$ carbon nanofibers (CNFs), ${ }^{16,17}$ and carbon aerogels. ${ }^{18}$

Among carbon nanomaterials, non-porous carbon onions, also known as onion-like carbon (OLC), have attracted major research interest as electrode materials for energy storage, for example, advanced anode electrodes for lithium ion batteries, ${ }^{19,20}$ pseudocapacitors, ${ }^{21,22}$ and ultrahigh-power electrical double-layer capacitors. ${ }^{23-25}$ The major attractions stem from the ability to prepare them on a large scale by thermal annealing of nanodiamonds and the superior power handling ability. ${ }^{26}$ OLCs are described as multi-shell fullerenes ${ }^{27}$ that, unlike fullerenes, exhibit a high electrical conductivity commonly in the range of $2-4 \mathrm{~S} \mathrm{~cm}^{-1} \cdot{ }^{25}$ However, the limited surface area of OLCs $\left(200-600 \mathrm{~m}^{2} \mathrm{~g}^{-1}\right)$ has also resulted in limited double-layer capacitance (usually between 25 and $50 \mathrm{~F} \mathrm{~g}^{-1}$, equivalent up to $2 \mathrm{~W} \mathrm{~h} \mathrm{~kg}^{-1}$ at $\left.1 \mathrm{~V}\right) .^{25,26}$

OLCs derived from thermal treatment of nanodiamonds $(\mathrm{NDs})^{28}$ are highly graphitic spherical particles $(5-10 \mathrm{~nm})$ that consist of several concentric carbon shells. ${ }^{29}$ Alternative synthesis methods may also yield larger OLCs with diameters of more than $10 \mathrm{~nm}$ (ref. 19 and 30) and include condensation of carbon vapor ${ }^{31}$ or electron beam irradiation. ${ }^{32}$ However, thermal annealing of $\mathrm{NDs}^{33}$ at temperatures between 1000 and $2000{ }^{\circ} \mathrm{C}$ is currently the preferred technique to synthesize OLCs since large amounts of material can be obtained per run. ${ }^{34}$ Also, a narrow size distribution of the ND precursor translates into a narrow size distribution of the resulting onion-like carbons. ${ }^{21}$ 
Birnessite-type $\mathrm{MnO}_{2}$ (in this paper referred to as just " $\mathrm{MnO}_{2}$ ") exhibits a two-dimensional layered structure (see ESI, Fig. S1†) displaying edge-sharing $\mathrm{MnO}_{6}$ octahedra in the sheets and metal cations (for example $\mathrm{K}^{+}$) and water molecules in the interlayer region. Hence, an appropriate chemical representation would be $\mathrm{K}_{x} \mathrm{Mn}_{2} \mathrm{O}_{4} \cdot y \mathrm{H}_{2} \mathrm{O}$ (with $x \leq 0.5$ and $y \leq 1.5$ ). ${ }^{35}$ This metal oxide has become an attractive electrode material for efficient and low-cost development of supercapacitors due to its natural abundance and environmental compatibility. ${ }^{\mathbf{3 6}-42}$ However, because of its low electrical conductivity $\left(10^{-6}\right.$ to $\left.10^{-5} \mathrm{~S} \mathrm{~cm}^{-1}\right)$ and poor power handling capability, the electrochemical performance of $\mathrm{MnO}_{2}$ electrodes is rather low, which significantly limits its potential applications as high-power supercapacitor electrodes. ${ }^{43}$ The capacitive performance, redox activity, as well as utilization of $\mathrm{MnO}_{2}$ can be enhanced by the addition of conductive materials. ${ }^{\mathbf{4 4 - 4 6}}$ However, the resulting performance strongly depends on the quality and properties of such carbon/metal oxide hybrid materials.

This work, for the first time, reports the electrochemistry of $\mathrm{MnO}_{2}$ integrated with highly graphitized OLCs derived from NDs (herein abbreviated simply as $\mathrm{OLC} / \mathrm{MnO}_{2}$ nanohybrid) as a high-power pseudocapacitor in a neutral aqueous medium ( $1 \mathrm{M} \mathrm{Na}_{2} \mathrm{SO}_{4}$ ). Previous studies related to $\mathrm{MnO}_{2}$ with "carbon onions" were carried out using low-graphitized materials obtained from either clarified butter ("Ghee") ${ }^{30}$ or phenolicformaldehyde resins with much larger particle diameters (tens of $\mathrm{nm}) .{ }^{42}$ Whilst these initial reports are encouraging, we show in this study that by using highly graphitized OLCs, OLC/ $\mathrm{MnO}_{2}$ nanohybrids exhibit a very high power density $\left(\sim 75 \mathrm{~kW} \mathrm{~kg}^{-1}\right)$. In addition, our devices show excellent capacitance retention upon long-hour voltage-holding and very low equivalent distribution resistance $\left(\mathrm{EDR} \approx 3 \Omega \mathrm{cm}^{2}\right.$ ) with a response time of just a few milliseconds.

\section{Experimental section}

\section{Precursor and synthesis of OLC and OLC/ $\mathrm{MnO}_{2}$}

OLC was synthesized from nanodiamond (ND) powder with a purity of 98-99\% (NaBond Technologies) and thoroughly characterized as recently described. ${ }^{47}$ Briefly, ND powder was placed in a closed-lid cylindrical graphite crucible $(30 \mathrm{~mm}$ in diameter and $20 \mathrm{~mm}$ in height) and thermally annealed in a water-cooled high temperature vacuum furnace with tungsten heaters (Model: 1100-3580-W1, Thermal Technology Inc.). The heating and cooling rates were both $15{ }^{\circ} \mathrm{C} \min ^{-1}$ and the chamber pressure ranged between 10 and $100 \mathrm{mPa}$. The final OLC was annealed at $1750{ }^{\circ} \mathrm{C}$ for $3 \mathrm{~h}$. The $\mathrm{OLC} / \mathrm{MnO}_{2}$ nanohybrid material was prepared using the conventional hydrothermal reduction technique. Typically, $40 \mathrm{mg}$ of OLC was dispersed by sonication in $30 \mathrm{~mL}$ of $0.02 \mathrm{M} \mathrm{KMnO}_{4}$ (Merck), and the mixture $(\mathrm{pH}=7.05)$ was refluxed at $130{ }^{\circ} \mathrm{C}$ in an oil bath for $24 \mathrm{~h}$ with continuous magnetic stirring. The resultant dispersion was then centrifuged and washed several times with deionized water, and finally dried at $60{ }^{\circ} \mathrm{C}$ overnight in a vacuum oven. All chemicals were of analytical grade and used as received. Deionized water was used throughout the synthesis process.

\section{Structural characterization}

Surface morphology characterization of the samples was obtained using a JSM-7500F (JEOL, Japan) scanning electron microscope (SEM) operated at $3.0 \mathrm{kV}$. Energy dispersive X-ray spectra (EDX) were recorded with an EDX system (Oxford Instruments) at 5 different positions. The chemical composition was calculated using the AZtec energy analysis software (Oxford Instruments). Transmission electron microscopy (TEM) samples were prepared by dispersing powders in ethanol and placing the dispersion over a copper grid with a lacey carbon film. All measurements were carried out with a $2100 \mathrm{~F}$ microscope (JEOL) operating at $200 \mathrm{kV}$. X-ray diffraction (XRD) patterns of the samples were collected using an X'Pert-Pro MPD diffractometer (PANalytical) with theta/theta geometry (step width: $0.0263^{\circ} \mathrm{s}^{-1}$ ), operating a copper tube at $40 \mathrm{kV}$ and $40 \mathrm{~mA}$. The instrumental resolution function was characterized with the NIST SRM 660a $\left(\mathrm{LaB}_{6}\right)$ standard. The patterns were recorded in the range of $5-148^{\circ} 2 \theta$. Qualitative phase analysis of the samples was conducted using Bruker EVA software using the PDF database.

Raman spectra were recorded with a Renishaw inVia Raman microscope using a Nd-YAG laser with an excitation wavelength of $532 \mathrm{~nm}$ and a grating with 1800 lines $\mathrm{mm}^{-1}$ yielding a spectral resolution of $c a .1 .2 \mathrm{~cm}^{-1}$. The spot size on the sample was in the focal plane ca. $2 \mu \mathrm{m}$ using an output power of $0.5 \mathrm{~mW}$. Spectra were recorded for $30 \mathrm{~s}$ and accumulated 50 times to eliminate cosmic rays and to obtain a high signal-to-noise and signal-to-background ratio. Peak fitting was achieved by employing Lorentzian peaks assuming four components for the carbon spectrum between 1000 and $1800 \mathrm{~cm}^{-1}$. Fourier infrared spectroscopy (FTIR) analyses were carried out using a Perkin Elmer FT-IR spectrophotometer. OLC and $\mathrm{OLC} / \mathrm{MnO}_{2}$ nanohybrids were analyzed as $\mathrm{KBr}$ pellets (10 scans).

X-ray photoelectron spectroscopy (XPS) experiments were carried out on a Kratos Axis Ultra-DLD system (Shimadzu) with monochromated $\mathrm{Al} \mathrm{K} \alpha$ radiation $(1486.6 \mathrm{eV})$. Binding energies were calibrated using the containment carbon (C 1s at $284.6 \mathrm{eV}$ ). The spectra analysis was performed with the XPS Peak 4.1 program and a Shirley function was used to subtract the background. The metal oxide content in the nanohybrid was determined by thermogravimetric analysis (TGA) using an STA Jupiter $449 \mathrm{C}$ (Netzsch) in an $\mathrm{Ar} / \mathrm{O}_{2}$ atmosphere at a temperature scan rate of $10 \mathrm{~K} \mathrm{~min}^{-1}$.

Nitrogen gas sorption measurements were made with a Quantachrome Autosorb iQ system. The samples were outgassed at $150{ }^{\circ} \mathrm{C}$ for $10 \mathrm{~h}$ under vacuum conditions. Gas sorption was performed in liquid nitrogen $\left(-196{ }^{\circ} \mathrm{C}\right)$ with a relative pressure range of $10^{-7}$ to 0.95 in 68 steps. The specific surface area (SSA) was calculated with the ASQwinsoftware using the Brunauer-Emmett-Teller (BET) equation $^{48}$ in the relative pressure range of $0.01-0.2$. We also calculated the SSA and pore size distribution (PSD) via quenched-solid density functional theory $(\mathrm{QSDFT})^{\mathbf{4 9}}$ with a hybrid model for slit and cylindrical pores and pore size between 0.56 and $37.5 \mathrm{~nm}$. 


\section{Electrochemical characterization}

All electrochemical measurements were carried out using a BioLogic VMP 300 potentiostat/galvanostat using either a threeelectrode (half-cell) or a two-electrode (full cell) configuration. For the three-electrode configuration a Pt disc and nickel foam were used as substrates for the working electrodes. For the three-electrode configuration using a Pt disc, a custom-built three-electrode cell ( $c f$. ref. 47 ) was used. The working electrode was prepared by drop-casting $7.1 \mathrm{mg} \mathrm{mL}^{-1}$ OLC colloidal dispersion (10 mass\% polyvinylidenfluoride, PVDF in ethanol) or $9.0 \mathrm{mg} \mathrm{mL}{ }^{-1} \mathrm{OLC} / \mathrm{MnO}_{2}$ nanohybrid colloidal dispersion (in anhydrous $N$-methyl-2-pyrrolidone, NMP) onto a Pt disc (diameter: $12 \mathrm{~mm}$, thickness: $100 \mu \mathrm{m}$, purity 99.99\%, Carl Schaefer) and dried at $80{ }^{\circ} \mathrm{C}$ overnight in a vacuum oven at $20 \mathrm{mbar}$ to remove the solvent. Polytetrafluoroethylene (PTFE) bound ( $5 \%$ in total electrode mass) activated carbon (YP50F, Kuraray Chemical) served as a counter electrode and was largely oversized in charge capacity as compared to the working electrode. A platinum wire (diameter $1 \mathrm{~mm}$, purity 99.99\%, Carl Schaefer) served as a pseudo-reference electrode. For the nickel foam based three-electrode configuration, the nickel foam (Celmet: thickness $=1.6 \mathrm{~mm}$, surface area $=7500 \mathrm{~m}^{2} \mathrm{~m}^{-3}$, cell size $=0.5 \mathrm{~mm}, 48-52$ cells per inch) was cleaned prior to use, in a $1 \mathrm{M} \mathrm{HCl}$ solution, washed with a copious amount of deionized water to a neutral $\mathrm{pH}$, and dried under vacuum. It was pasted with a mixture of $\mathrm{OLC} / \mathrm{MnO}_{2}$ nanohybrid, carbon black (CB, Degussa), and polyvinylidene fluoride (PVDF) (mass\% of 80 : 15 : 5 respectively, homogeneously mixed with a few drops of anhydrous $N$-methyl-2-pyrrolidone using a paste pestle and mortar). The CB and PVDF served as a conductive additive and a binder, respectively. The electrode was then dried at $80{ }^{\circ} \mathrm{C}$ overnight in a vacuum oven, and pressed to a thickness of $250 \mu \mathrm{m}$. The electrode was cut into a piece of $1 \mathrm{~cm} \times 1 \mathrm{~cm}$, while

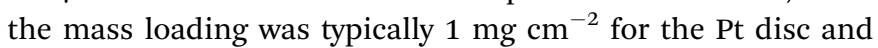
nickel foam. An oversized glassy carbon plate $\left(1.6 \times 1.6 \mathrm{~cm}^{2}\right)$ was used as the counter electrode and $\mathrm{Ag} / \mathrm{AgCl}(3 \mathrm{M} \mathrm{KCl})$ as the reference electrode. The two-electrode configuration used the nickel foam as substrate. Both the positive and negative electrodes used nickel foam coated with the $\mathrm{OLC} / \mathrm{MnO}_{2}$ nanohybrid, obtained as described for the three-electrode above. The resulting slurry was coated onto the nickel foam substrate $\left(\sim 3 \mathrm{~cm}^{2}\right)$ with a spatula using an average mass loading of $1 \mathrm{mg} \mathrm{cm} \mathrm{cm}^{-2}$. Symmetric cells were also prepared using nickel foam loaded with only OLC. In all experiments, $1 \mathrm{M} \mathrm{Na}_{2} \mathrm{SO}_{4}$ was used as the electrolyte and a porous glass fiber (Whatman Grade GF/D Glass Microfiber Filters, Sigma-Aldrich) served as the separator. For the three-electrode configuration, cyclic voltammetry was performed at various scan rates $\left(2-100 \mathrm{mV} \mathrm{s}^{-1}\right)$. Voltage-holding (floating) experiments were performed for $10 \mathrm{~h}$ at $0.8 \mathrm{~V}$, then galvanostatically charged-discharged between 0.0 and $0.8 \mathrm{~V}$ at $1 \mathrm{~A} \mathrm{~g}^{-1}$, repeating the process five times (i.e., a total of $50 \mathrm{~h}$ ). Electrochemical impedance spectroscopy (EIS) data were obtained between $100 \mathrm{kHz}$ and $10 \mathrm{mHz}$ with a perturbation amplitude (rms value) of the AC signal of $2 \mathrm{mV}$. Every EIS experiment was performed after allowing the cell to equilibrate for $5 \mathrm{~min}$ at the chosen fixed potential.
The specific capacitance $\left(C_{\mathrm{sp}}\right)$ of the half-cells, obtained from $\mathrm{CV}$ and galvanostatic discharge curves, was evaluated using the established equations (1) and (2), respectively.

$$
\begin{gathered}
C_{\text {sp }}\left(\mathrm{F} \mathrm{g}^{-1}\right)=\frac{\int i \mathrm{~d} t}{\Delta V m} \\
C_{\text {sp }}\left(\mathrm{F} \mathrm{g}^{-1}\right)=\frac{i \Delta t}{\Delta V m}
\end{gathered}
$$

where $i(\mathrm{~A})$ is the current, $\Delta V(\mathrm{~V}) / \Delta t(\mathrm{~s})$ the slope of the discharge curve, and $m(\mathrm{~g})$ the mass of the active electrode, and $V(\mathrm{~V})$ is the voltage obtained during charge. Note that the iR drop ranged from 3.2 to $1.1 \Omega$ at current densities of $0.1-10 \mathrm{~A} \mathrm{~g}^{-1}$.

The specific capacitance $\left(C_{\mathrm{sp}}\right)$, maximum specific power density $\left(P_{\max }\right)$ and specific energy density $\left(E_{\mathrm{sp}}\right)$ for the full cells (symmetric devices) were evaluated from the slope of the charge-discharge curves using eqn (3)-(6). ${ }^{1}$

$$
\begin{gathered}
C(\mathrm{~F})=\frac{i}{\Delta V / \Delta t} \\
C_{\text {sp }}\left(\mathrm{F} \mathrm{g} \mathrm{g}^{-1}\right)=\frac{4 C}{m} \\
P_{\max }\left(10^{3} \mathrm{~W} \mathrm{~kg}^{-1}\right)=\frac{V^{2}}{4 m R_{\mathrm{s}}} \\
E\left(\frac{1}{3.6} \mathrm{Wh} \mathrm{kg}^{-1}\right)=\frac{C V^{2}}{2 m}
\end{gathered}
$$

where $i(\mathrm{~A})$ is the applied current, $\Delta V(\mathrm{~V}) / \Delta t(\mathrm{~s})$ the slope of the discharge curve and $m(\mathrm{~g})$ the total mass of both electrodes, $C(\mathrm{~F})$ the calculated capacitance, $V(\mathrm{~V})$ is the maximum voltage obtained during charge, and $R_{\mathrm{S}}$ is the equivalent series resistance (ESR).

\section{Results and discussion}

\section{SEM, TEM, and gas sorption analysis}

The surface morphologies of OLC and the $\mathrm{OLC} / \mathrm{MnO}_{2}$ nanohybrid studied using SEM are shown in Fig. 1a and $\mathrm{c}$ and using TEM in Fig. $1 b$ and d. The primary particle size of carbon onions is in the range of a few nanometers as seen from the TEM images in agreement with our previous findings. ${ }^{47}$ This primary particle size is maintained for the $\mathrm{OLC} / \mathrm{MnO}_{2}$ nanohybrid. Compared with OLC, OLC/ $\mathrm{MnO}_{2}$ hybrid nanoparticles exhibited an obviously different morphology. The selected area electron diffraction (SAED) pattern in the inset of Fig. 1d shows lattice fringes for crystalline $\mathrm{MnO}_{2}$ and circular lattice shells for OLC. ${ }^{30}$ Rather than a monolayer or multilayer coating of each carbon onion, an effective $\mathrm{OLC} / \mathrm{MnO}_{2}$ nanohybrid was obtained with nanodomains of highly mixed graphitic carbon and metal oxide. The amount of metal oxide was determined by TGA to represent 47 mass\% of the $\mathrm{OLC} / \mathrm{MnO}_{2}$ nanohybrid material (see ESI, Fig. S2 $\dagger$ ). Also, the TGA data show the excellent thermal stability of OLC with an onset of oxidation at around $630{ }^{\circ} \mathrm{C}$ as a result of the highly graphitic character of carbon onions synthesized at $1750{ }^{\circ} \mathrm{C}$. 

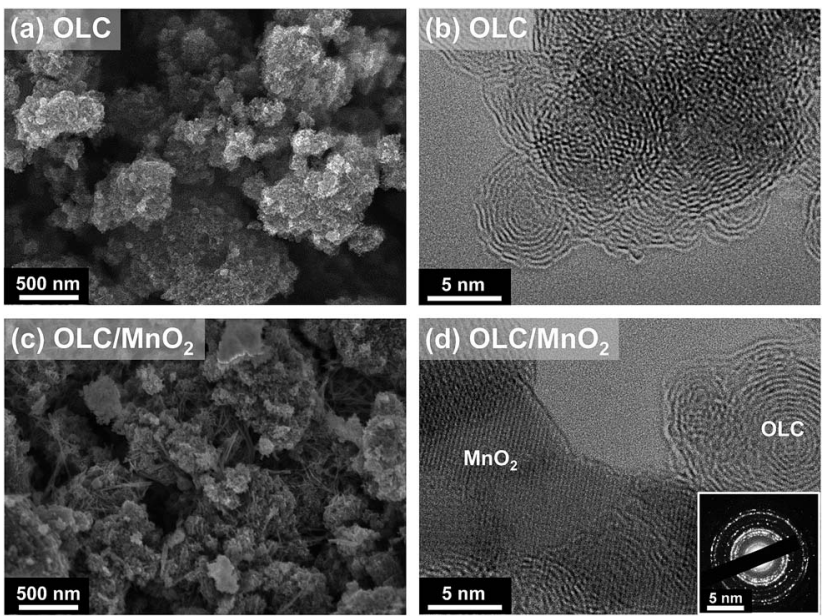

Fig. 1 SEM images of (a) OLC and (c) the $\mathrm{OLC} / \mathrm{MnO}_{2}$ nanohybrid; TEM images of (b) OLC and (d) the $\mathrm{OLC} / \mathrm{MnO}_{2}$ nanohybrid. The inset is the corresponding SAED pattern of (d).

Fig. 2 shows nitrogen gas sorption data for OLC and the OLC/ $\mathrm{MnO}_{2}$ nanohybrid. As we see, OLC/ $\mathrm{MnO}_{2}$ exhibits a QSDFT SSA of $122 \mathrm{~m}^{2} \mathrm{~g}^{-1}$ with a distribution of micropores $(<2 \mathrm{~nm})$ and mesopores (between 2 and $50 \mathrm{~nm}$ ). This represents a severe loss

(a)

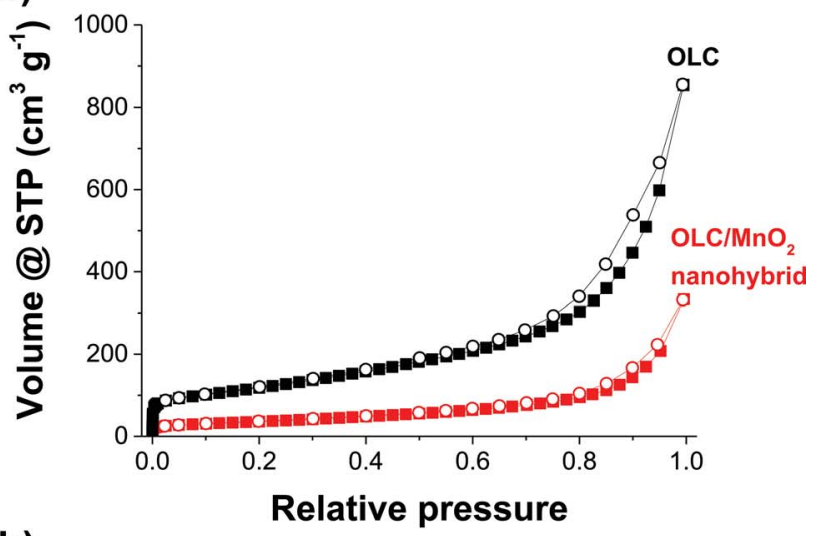

(b)

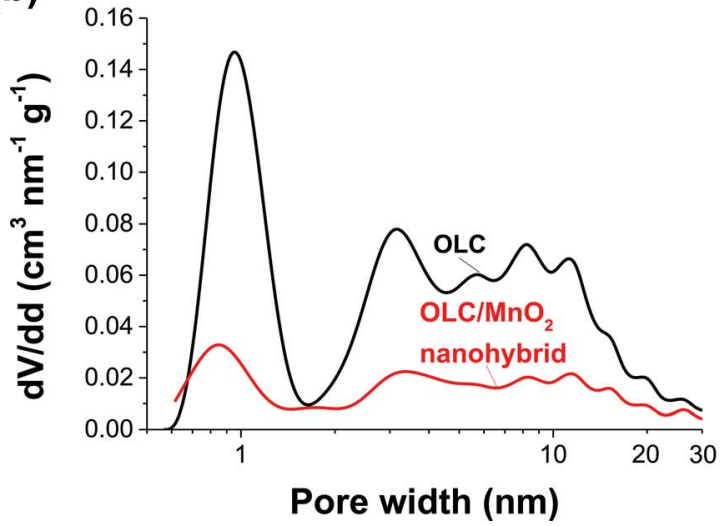

Fig. 2 (a) Nitrogen adsorption-desorption isotherms at $-196^{\circ} \mathrm{C}$ and (b) QSDFT pore size distribution overlays of OLC and the $\mathrm{OLC} / \mathrm{MnO}_{2}$ nanohybrid. in the specific surface area compared to OLC with a QSDFT SSA of $391 \mathrm{~m}^{2} \mathrm{~g}^{-1}$ and is mostly related to the higher molecular mass and higher density of $\mathrm{MnO}_{2}$ in addition to pore blocking. ${ }^{50}$ Yet, Fig. 2b shows that the overall pore size distribution is preserved after the addition of $\mathrm{MnO}_{2}$ at a lower total pore volume.

\section{XRD, Raman, FTIR, EDX, and XPS studies}

Fig. 3 illustrates the Raman spectra, X-ray diffraction patterns, and FTIR spectra of OLC and the corresponding $\mathrm{OLC} / \mathrm{MnO}_{2}$ nanohybrid material. The presence of $\mathrm{MnO}_{2}$ is confirmed by a strong Raman signal at around $565 \mathrm{~cm}^{-1},{ }^{51}$ (Fig. 3a). The presence of the OLC in the hybrid from the XRD analysis is confirmed by Raman peaks associated with the carbon D-mode $\left(1350 \mathrm{~cm}^{-1}\right)$ and G-mode $\left(1590 \mathrm{~cm}^{-1}\right)$ of $\mathrm{OLC} / \mathrm{MnO}_{2}$. Peak analysis (Fig. 3a) shows that the hydrothermal synthesis only insignificantly changes the OLC structure: both the D- and G-mode remain almost unchanged. In particular, the $I_{\mathrm{D}} / I_{\mathrm{G}}$ ratios before and after $\mathrm{MnO}_{2}$ deposition are almost identical to the values of 1.20 and 1.25, respectively. The FWHM values for both the D-mode and the G-mode were measured to be $73.1 \mathrm{~cm}^{-1}$ and $69.8 \mathrm{~cm}^{-1}$ before the deposition and to be $78.5 \mathrm{~cm}^{-1}$ and $65.4 \mathrm{~cm}^{-1}$ after the $\mathrm{MnO}_{2}$ deposition. The only minor change related to the carbon signal is identified at around 1100 to $1200 \mathrm{~cm}^{-1}$ which may indicate the formation of a small amount of functionalized carbon. ${ }^{52}$ FTIR was used to study further the electrode materials as shown by Fig. 3c. The well pronounced peak at $550 \mathrm{~cm}^{-1}$ is due to the $\mathrm{Mn}-\mathrm{O}-\mathrm{Mn}$ asymmetric stretching vibration. The broad peak at $3450 \mathrm{~cm}^{-1}$ is assigned to hydroxyl groups which suggests that there are water molecules in the interlayers (see also the structure given in the ESI, Fig. $\mathrm{S} 1 \dagger){ }^{53}$

From the XRD patterns of the $\mathrm{OLC} / \mathrm{MnO}_{2}$ nanohybrid (Fig. 3b), the peak at around $26^{\circ} 2 \theta$ is associated with the (002) plane of graphitic carbon and it can be observed also in $\mathrm{OLC} / \mathrm{MnO}_{2}$ diffractograms indicating the presence of carbon in the nanohybrid. The other peaks can be indexed to birnessitetype $\mathrm{MnO}_{2}$ (PDF 42-1317). All diffraction peaks of the metal oxide are broadened which indicates the nanocrystalline nature of the $\mathrm{MnO}_{2}$ with an average coherence length (domain size) in the range of 5-10 $\mathrm{nm}$. The calculated carbon $d$-spacing for the (002) plane is $0.352 \mathrm{~nm}$ and remains at that value with or without the presence of $\mathrm{MnO}_{2}$. This represents a small increase in lattice spacing compared to an ideal graphite crystal (i.e., $0.344 \mathrm{~nm}$ ) as is well-known for the carbon onion structure. ${ }^{52}$

Chemical analysis confirms the presence of birnessite, meaning, not of pure $\mathrm{MnO}_{2}$ but of a material following the average formula $\mathrm{K}_{x} \mathrm{Mn}_{2} \mathrm{O}_{4} \cdot y \mathrm{H}_{2} \mathrm{O}$. Semi-quantitative analysis of OLC EDX spectra (Fig. 4a and Table 1) shows less than 0.2 mass\% of impurities alongside ca. 9 mass\% of surface oxygen. The metal oxide shows an average molar Mn : K ratio of $4.6: 1$ which is somewhat larger than the maximum stoichiometric value of $4: 1$. The small difference might indicate the presence of minor amounts of residual $\mathrm{KMnO}_{4}$. Yet, we note that the previously reported non-carbon content of around 47 mass\% is in agreement with our EDX data (54.3 mass\%). 

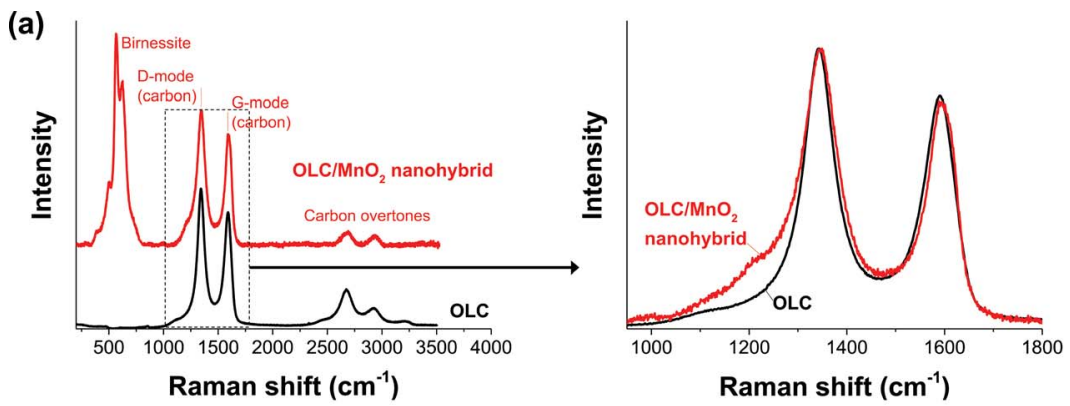

(b)

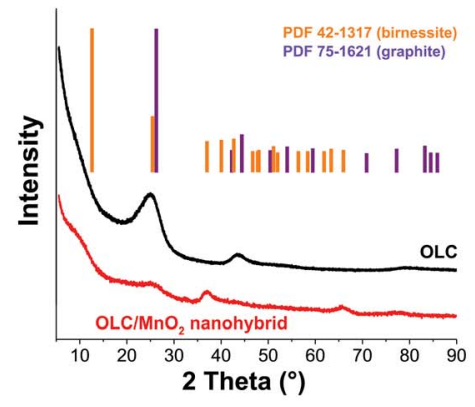

(c)

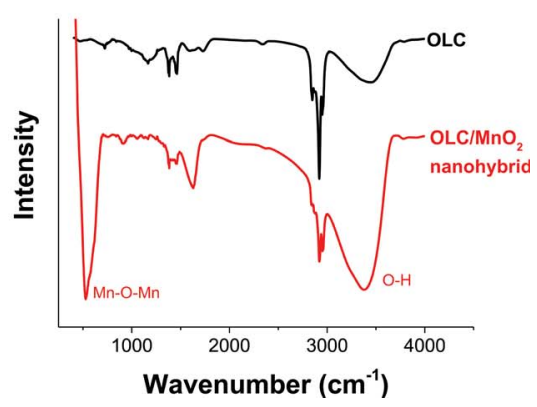

Fig. 3 (a) Raman spectra, (b) X-ray diffraction pattern, and (c) FTIR spectra of OLC and the OLC/MnO 2 nanohybrid.

(a)

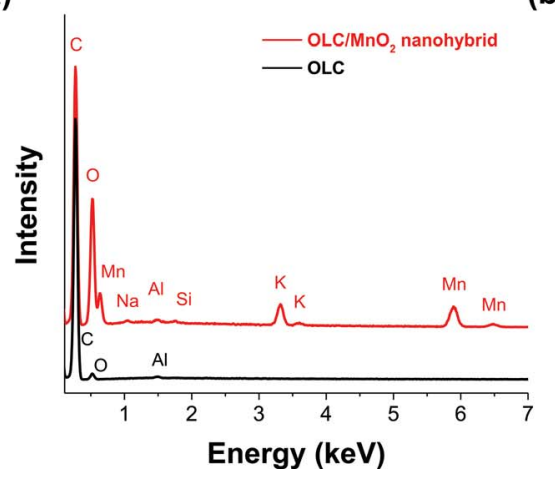

(b)

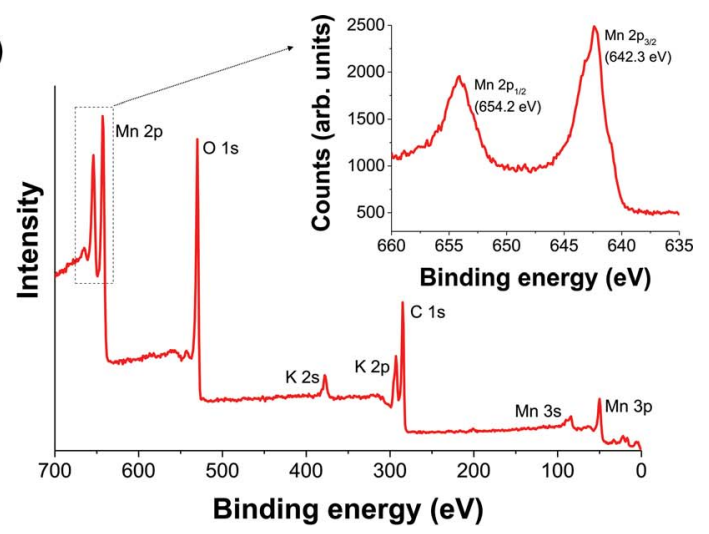

Fig. 4 (a) Energy dispersive X-ray (EDX) spectra of OLC and the OLC/MnO 2 nanohybrid and (b) X-ray photoelectron spectrum (XPS) of the $\mathrm{OLC} / \mathrm{MnO}_{2}$ nanohybrid.

Only minor impurities of $\mathrm{Si}$ and $\mathrm{Na}$ can be detected which stem from impurities in the $\mathrm{KMnO}_{4}$. XPS analysis of $\mathrm{OLC} / \mathrm{MnO}_{2}$ (Fig. 4b) shows the binding energy peaks of $\mathrm{Mn}$ and C. The Mn $2 p$ region consisted of a spin-orbit doublet with $\mathrm{Mn} 2 \mathrm{p}_{1 / 2}$ and Mn $2 \mathrm{p}_{3 / 2}$ having binding energies of $654.2 \mathrm{eV}$ and $642.3 \mathrm{eV}$, respectively. ${ }^{54}$ The energy separation between $\mathrm{Mn} 2 \mathrm{p}_{1 / 2}$ and $\mathrm{Mn}$ $2 \mathrm{p}_{3 / 2}$ of $11.9 \mathrm{eV}$ is an indication of $\mathrm{Mn}$ in a +4 oxidation state. ${ }^{55-57}$ From the XPS survey scan, we also see the presence of significant amounts of $\mathrm{K}$ in addition to $\mathrm{Mn}, \mathrm{C}$, and $\mathrm{O}$.

\section{Comparative performance of half-cells with Pt disc or Ni foam}

Fig. 5 and 6 compare the electrochemical performance of the three-electrode configurations using either a platinum disc (Fig. 5) or nickel foam (Fig. 6) as current collectors. The CV curves of OLC (Fig. 5a) are characteristic of double-layer capacitive materials, while the $\mathrm{CV}$ curve of the $\mathrm{OLC} / \mathrm{MnO}_{2}$ nanohybrid shows redox-peaks indicative of faradaic reactions (Fig. 6a). The same conclusions can be drawn from the galvanostatic charge-discharge profiles (Fig. $5 \mathrm{~b}$ and $\mathrm{c} v s$. Fig. $6 \mathrm{~b}$ and c) ${ }^{58,59}$ We also see a high power handling ability of the materials with a comparatively small drop in the specific capacitance of $\mathrm{OLC} / \mathrm{MnO}_{2}\left(335-180 \mathrm{~F} \mathrm{~g}^{-1}\right)$ as a function of the current density $\left(0.3-32 \mathrm{~A} \mathrm{~g}^{-1}\right)$, Fig. $6 \mathrm{~d}$.

The key findings from Fig. 5 and 6 may be summarized as follows: (i) the specific capacitance of $\mathrm{OLC} / \mathrm{MnO}_{2}$ is more than a magnitude higher than that of OLC for both current collectors (i.e., $\mathrm{Ni}$ foam and a Pt disc); (ii) both types of current collectors gave an essentially similar specific capacitance at different current densities (e.g., $250 \mathrm{~F} \mathrm{~g}^{-1}$ at $5 \mathrm{~A} \mathrm{~g}^{-1}$ ); and (iii) the stable voltage window for the Pt disc is narrower $(0-0.5 \mathrm{~V})$ than that of 
Table 1 Chemical composition of OLC and the $\mathrm{OLC} / \mathrm{MnO}_{2}$ nanohybrid measured by EDX in mass\% and atom\%

\begin{tabular}{|c|c|c|c|c|c|c|c|}
\hline (Mass\%) & $\mathrm{C}$ & $\mathrm{O}$ & $\mathrm{Na}$ & $\mathrm{Al}$ & $\mathrm{Si}$ & $\mathrm{K}$ & $\mathrm{Mn}$ \\
\hline OLC & $90.8 \pm 1.7$ & $9.1 \pm 1.7$ & - & $0.2 \pm 0.1$ & - & - & - \\
\hline $\mathrm{OLC} / \mathrm{MnO}_{2}$ & $45.7 \pm 1.4$ & $20.3 \pm 1.9$ & $0.2 \pm 0.1$ & $0.3 \pm 0.1$ & $0.2 \pm 0.1$ & $4.5 \pm 1.2$ & $28.9 \pm 2.6$ \\
\hline (Atom\%) & $\mathrm{C}$ & $\mathrm{O}$ & $\mathrm{Na}$ & $\mathrm{Al}$ & $\mathrm{Si}$ & $\mathrm{K}$ & Mn \\
\hline OLC & $93.0 \pm 1.3$ & $7.0 \pm 1.3$ & - & $0.1 \pm 0.1$ & - & - & - \\
\hline
\end{tabular}
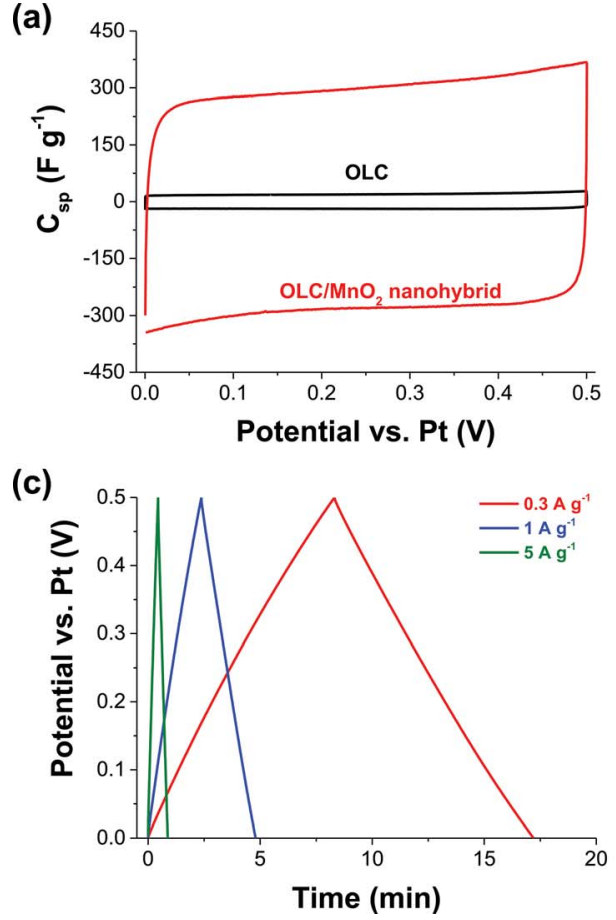

(b)

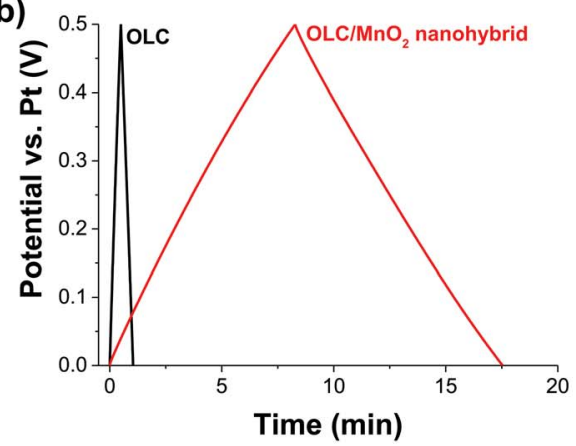

(d)

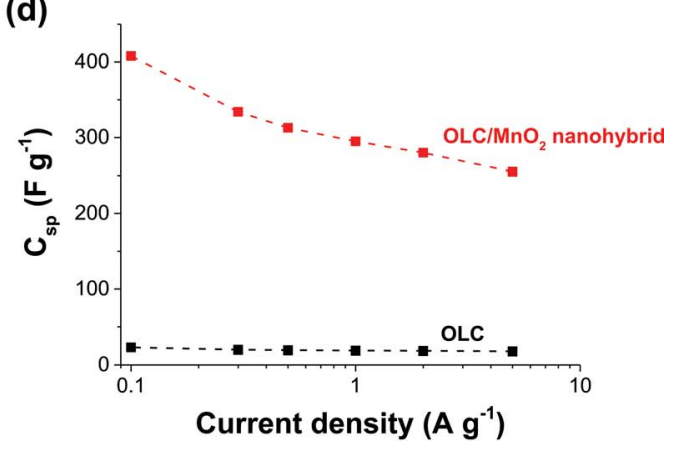

Fig. 5 3-electrode configuration with a Pt disc as the current collector: (a) cyclic voltammograms at $2 \mathrm{mV} \mathrm{s}^{-1}$, (b) galvanostatic chargedischarge curves at $0.3 \mathrm{~A} \mathrm{~g}^{-1}$ comparing OLC and the $\mathrm{OLC} / \mathrm{MnO}_{2}$ nanohybrid, (c) galvanostatic charge-discharge curves for the OLC/MnO nanohybrid at various current densities, and (d) Csp vs. current densities of the $\mathrm{OLC} / \mathrm{MnO}_{2}$ nanohybrid. Electrolyte: aqueous $1 \mathrm{M} \mathrm{Na} \mathrm{SO}_{4}$.

the nickel foam $(0-1.0 \mathrm{~V})$. The nickel foam alone only insignificantly contributes to the charge storage mechanism (see ESI, Fig. $\mathrm{S} 3 \dagger)$. We also note that carbon onions alone, that is without the presence of $\mathrm{MnO}_{2}$, only exhibit a low specific capacitance of $12 \mathrm{~F} \mathrm{~g}^{-1}$.

As summarized in Table 2, the maximum $C_{\mathrm{sp}}$ values for our 3-electrode tests (335-408 $\mathrm{F} \mathrm{g}^{-1}$ between 0.1 and $0.3 \mathrm{~A} \mathrm{~g}^{-1}$ ) are much higher than those recorded in the literature. The impressive value $\left(603 \mathrm{~F} \mathrm{~g}^{-1}\right.$ at $10 \mathrm{~A} \mathrm{~g}^{-1}$ ) for electrodeposited $\mathrm{MnO}_{2}$-nanopillars reported by $\mathrm{Yu}$ et $a l^{73}$ for their flexible nanostructured electrode obtained by combined sputtercoating and electrodeposition ( $\mathrm{PAN} / \mathrm{Au}-\mathrm{Pd} / \mathrm{MnO}_{2}$, i.e., comprised of a cocktail of polyacrylonitrile polymer and very expensive precious metals of palladium and gold) may, amongst other factors, be related to the thin film nature of their system and the mass of active materials used in their calculations. Our values are somewhat comparable to those of the recent work by
Ruoff et al..$^{39}$ involving the elaborate preparation of mesoporous nanotubes assembled from interwoven ultrathin birnessite-type $\mathrm{MnO}_{2}$ nanosheets. Note that our result is much higher than that of the "OLC"/ $\mathrm{MnO}_{2}\left(\sim 190 \mathrm{~F} \mathrm{~g}^{-1}\right.$ at $\left.0.2 \mathrm{~A} \mathrm{~g}^{-1}\right)$ reported by Wang et al., ${ }^{42}$ and the disparity can be related to the high graphitization of our OLC.

\section{Symmetric pseudocapacitor with a nickel foam substrate}

Further investigation of the OLC and OLC/ $\mathrm{MnO}_{2}$ as a full cell symmetric supercapacitor was carried out using nickel foam as the current collector considering its lower cost and better performance at half-cell experiments compared to platinum. Fig. 7 shows CVs (Fig. 7a and c) and galvanostatic chargedischarge curves (Fig. $7 \mathrm{~b}$ and d) of the OLC and OLC/ $\mathrm{MnO}_{2}$ nanohybrid. In agreement with the three-electrode experiment, two-electrode data of the OLC/ $\mathrm{MnO}_{2}$ nanohybrid show much higher gravimetric capacitance compared to OLC electrodes. 
(a)

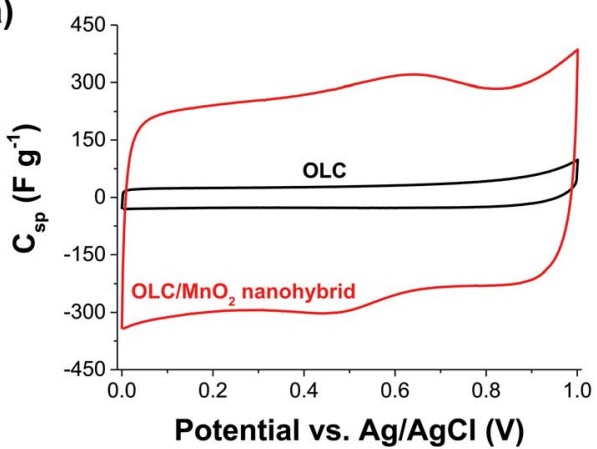

(c)

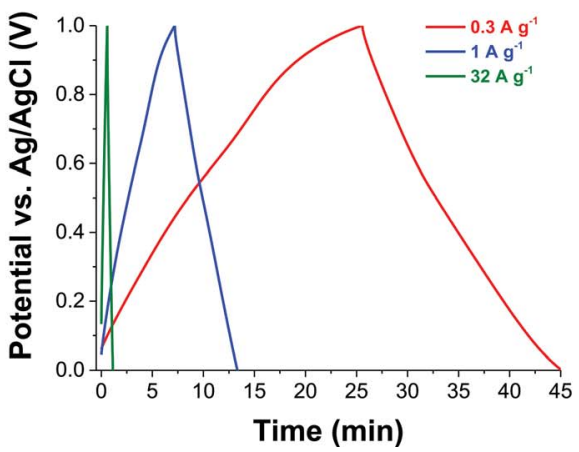

(b)

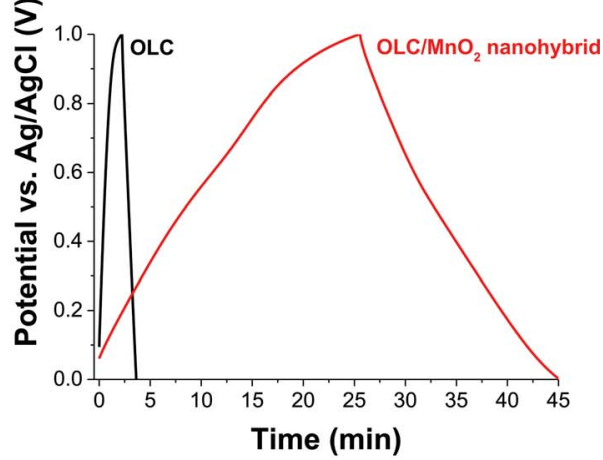

(d)

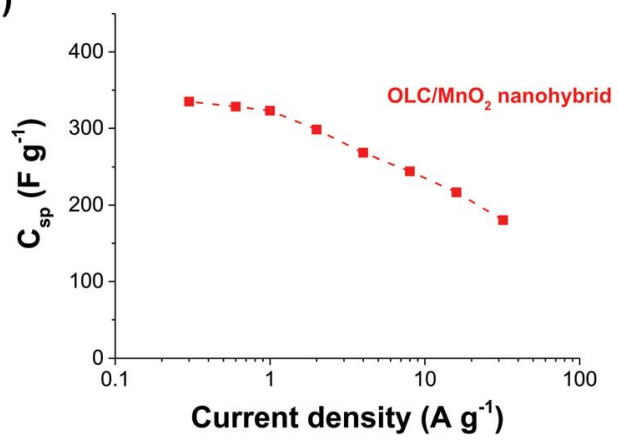

Fig. 6 3-electrode configuration with nickel foam as the current collector: (a) cyclic voltammograms at $5 \mathrm{mV} \mathrm{s}^{-1}$ and (b) galvanostatic chargedischarge curves at $0.3 \mathrm{~A} \mathrm{~g}^{-1}$ comparing $\mathrm{OLC}$ and the $\mathrm{OLC} / \mathrm{MnO}_{2}$ nanohybrid, (c) galvanostatic charge-discharge curves for the OLC/MnO 2 nanohybrid at various current densities, and (d) $C_{\mathrm{sp}}$ vs. current densities of the $\mathrm{OLC} / \mathrm{MnO}_{2}$ nanohybrid. Electrolyte: aqueous $1 \mathrm{M} \mathrm{Na}_{2} \mathrm{SO}_{4}$.

Table 2 Comparison of specific capacitance of various $\mathrm{MnO}_{2}$-based three-electrode systems

\begin{tabular}{|c|c|c|c|c|}
\hline Samples & Electrolyte & $C_{\mathrm{sp}}\left(\mathrm{F} \mathrm{g}^{-1}\right)$ & $i\left(\mathrm{~A} \mathrm{~g}^{-1}\right)$ & References \\
\hline Birnessite-type $\mathrm{MnO}_{2}$ & $1 \mathrm{M} \mathrm{Na}_{2} \mathrm{SO}_{4}$ & $335-408$ & $0.1-0.3$ & This work \\
\hline Birnessite-like hollow $\mathrm{MnO}_{2}$ & $1 \mathrm{M} \mathrm{Na}_{2} \mathrm{SO}_{4}$ & 169 & 0.25 & 37 \\
\hline Birnessite-type $\mathrm{MnO}_{2}$ nanotube & $1 \mathrm{M} \mathrm{Na}_{2} \mathrm{SO}_{4}$ & 365 & 0.25 & 39 \\
\hline Birnessite-type $\mathrm{MnO}_{2}$ & $1 \mathrm{M} \mathrm{Na}_{2} \mathrm{SO}_{4}$ & 210 & 1 & 40 \\
\hline Birnessite-type $\mathrm{MnO}_{2}$ nanosheet & $1 \mathrm{M} \mathrm{Na}_{2} \mathrm{SO}_{4}$ & 269 & 0.3 & 41 \\
\hline$\alpha-\mathrm{MnO}_{2}$ ultralong nanowire & $0.5 \mathrm{M} \mathrm{Na}_{2} \mathrm{SO}_{4}$ & 345 & 1 & 64 \\
\hline$\alpha-\mathrm{MnO}_{2}$ spherical-like particle & $1 \mathrm{M} \mathrm{Na}_{2} \mathrm{SO}_{4}$ & 259 & 0.1 & 65 \\
\hline$\alpha-\mathrm{MnO}_{2}$ sphere & $0.25 \mathrm{M} \mathrm{Na}_{2} \mathrm{SO}_{4}$ & 200 & 1 & 66 \\
\hline $\mathrm{MnO}_{2}$ nanosheet & $0.1 \mathrm{M} \mathrm{Na}_{2} \mathrm{SO}_{4}$ & 182 & 0.1 & 67 \\
\hline $\mathrm{MnO}_{2}$ microsphere & $1 \mathrm{M} \mathrm{Na}_{2} \mathrm{SO}_{4}$ & 190 & 0.5 & 68 \\
\hline $\mathrm{MnO}_{2}$ nanosheet array & $1 \mathrm{M} \mathrm{Na}_{2} \mathrm{SO}_{4}$ & 201 & 1 & 69 \\
\hline
\end{tabular}

The $\mathrm{OLC} / \mathrm{MnO}_{2}$ is capable of cycling at very high current densities (up to $10 \mathrm{~A} \mathrm{~g}^{-1}$, Fig. 7d), yielding a high specific capacitance suitable for high power energy storage applications.

Table 3 summarizes the values of the capacitance parameters obtained in comparison with the literature, and it is evident that the $\mathrm{OLC} / \mathrm{MnO}_{2}$ nanohybrid exhibits higher performance (in terms of power density or rate capability) than many state-of- the-art $\mathrm{MnO}_{2}$-based pseudocapacitors. Note that there has been no known report on symmetric supercapacitors based on birnessite-type $\mathrm{MnO}_{2}$ in the literature so far; yet, the latter is important to transition to actual devices.

Voltage-holding (or floating) experiments represent a reliable analysis method for establishing the long-term stability of supercapacitor electrodes. ${ }^{60,61}$ In this work, the $\mathrm{OLC} / \mathrm{MnO}_{2}$ 

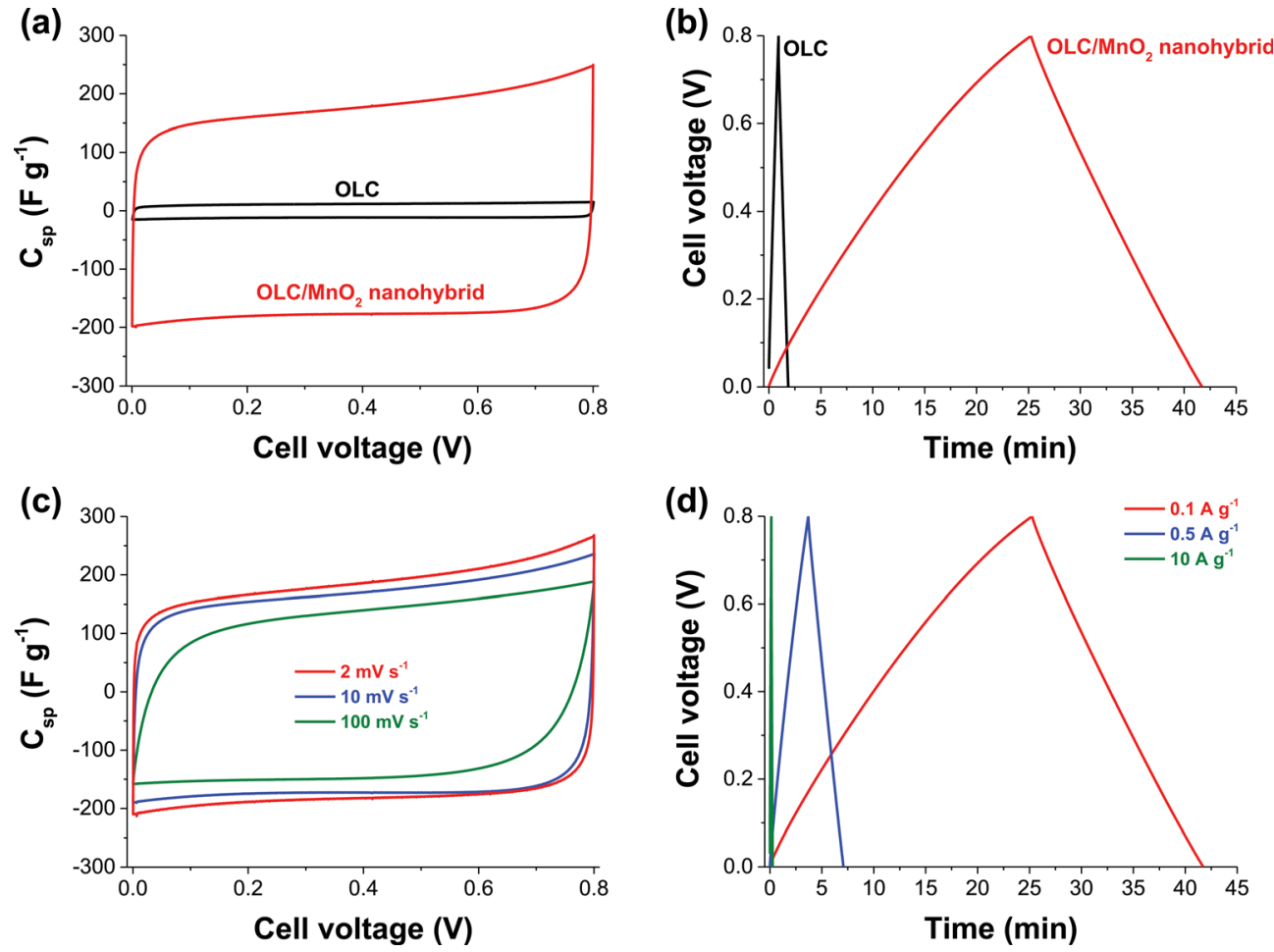

Fig. 7 Nickel foam based 2-electrode (symmetric) configuration: (a) comparative cyclic voltammograms for OLC and $\mathrm{OLC}_{\mathrm{MnO}}$ at $5 \mathrm{mV} \mathrm{s}^{-1}$, (b) comparative galvanostatic charge-discharge curves for OLC and OLC/MnO 2 at $0.1 \mathrm{~A} \mathrm{~g}^{-1}$, (c) CVs at different scan rates for OLC/MnO 2 and (d) comparative galvanostatic charge-discharge curves for $\mathrm{OLC}$ and the $\mathrm{OLC} / \mathrm{MnO}_{2}$ nanohybrid at different current densities. Electrolyte: aqueous $1 \mathrm{M} \mathrm{Na}_{2} \mathrm{SO}_{4}$.

Table 3 Comparison of electrochemical performance of some $\mathrm{MnO}_{2}$-based aqueous symmetric electrochemical capacitors ${ }^{a}$

\begin{tabular}{|c|c|c|c|c|c|c|c|}
\hline Electrode & Electrolyte & $V_{\max }(\mathrm{V})$ & $C_{\mathrm{sp}}\left(\mathrm{F} \mathrm{g}^{-1}\right)$ & $E_{\mathrm{sp}}\left(\mathrm{W} \mathrm{h} \mathrm{kg}^{-1}\right)$ & $P_{\max }\left(\mathrm{kW} \mathrm{kg}^{-1}\right)$ & ${ }^{\#} \operatorname{EDR}\left(\Omega \mathrm{cm}^{2}\right)$ & References \\
\hline OLC & $1 \mathrm{M} \mathrm{Na}_{2} \mathrm{SO}_{4}$ & 0.8 & 12 & 0.3 & 2.9 & 7.8 & This work \\
\hline $\mathrm{OLC} / \mathrm{MnO}_{2}$ & $1 \mathrm{M} \mathrm{Na}_{2} \mathrm{SO}_{4}$ & 0.8 & 254 & 5.6 & 74.8 & 3.1 & This work \\
\hline $\mathrm{C} / \mathrm{MnO}_{2}$ DNTAs & $1 \mathrm{M} \mathrm{Na}_{2} \mathrm{SO}_{4}$ & 0.8 & 161 & 35.0 & 16.0 & $\sim 20$ & 75 \\
\hline $\mathrm{CNOs} / \mathrm{MnO}_{2}$ & $0.5 \mathrm{M} \mathrm{H}_{2} \mathrm{SO}_{4}$ & 1.0 & 575 & 30.1 & 17.9 & $\sim 7$ & 30 \\
\hline $\mathrm{GN}-\left(\gamma-\mathrm{MnO}_{2} / \mathrm{CNT}\right)$ & $6 \mathrm{M} \mathrm{KOH}$ & 1.0 & 310 & 43.0 & 26.0 & $\sim 3.2$ & 76 \\
\hline
\end{tabular}

${ }^{a}$ Key: GN = graphene nanosheet; $\mathrm{GF}=$ graphene foam; $\mathrm{CNT}=$ carbon nanotube; DNTA = double-walled nanotube array; CNOs = carbon nanoonions; PDDA: polydiallyldimethylammonium chloride. ${ }^{\#}$ The EDR (equivalent distributed resistance) values were obtained prior to stability studies, and were converted to the $\Omega \mathrm{cm}^{2}$ based on the information we extracted from the cited reports.

nanohybrid exhibited excellent stability during voltage-holding over $50 \mathrm{~h}$ at $1 \mathrm{~A} \mathrm{~g}^{-1}$ (see ESI, Fig. S4 $\dagger$ ). This performance has been illustrated by the gradual decrease in the specific capacitance as the current is kept constant at high potential, retaining ca. $200 \mathrm{~F} \mathrm{~g}^{-1}$ (i.e., approximately $90 \%$ of its initial capacitance of $220 \mathrm{~F} \mathrm{~g}^{-1}$ ). The excellent stability of the $\mathrm{OLC} / \mathrm{MnO}_{2}$ nanohybrid showed that this device can be charged and discharged without significant deterioration. These values correspond to a maximum specific energy of $5.6 \mathrm{~W} \mathrm{~h} \mathrm{~kg}^{-1}$ and an excellent power density of $74.8 \mathrm{~kW} \mathrm{~kg}^{-1}$. The improved performance of this hybrid symmetric pseudocapacitor is attributed to the combination of the high electrical conductivity of OLC and the highly reversible redox reactions (pseudocapacitance) arising from the nanostructured $\mathrm{MnO}_{2}$ material.
EIS data were acquired prior to and post-floating experiments for the OLC/ $\mathrm{MnO}_{2}$ nanohybrid material (Fig. 8 and ESI, Fig. S5 $\dagger$ ) and OLC alone (see ESI, Fig. S6†). The equivalent distributed resistance (EDR), comprising both the equivalent series resistance (ESR) and the ionic resistance within the porous structure (i.e., RC semicircle), was obtained by extrapolating the vertical portion of the plot to the real axis. The OLC/ $\mathrm{MnO}_{2}$ device shows a lower EDR $\left(3.1 \Omega \mathrm{cm}^{2}\right)$ compared to the OLC alone $\left(7.8 \Omega \mathrm{cm}^{2}\right)$. However, the RC semicircle for the OLC/ $\mathrm{MnO}_{2}$ is slightly bigger $\left(\sim 1.8 \Omega \mathrm{cm}^{2}\right)$ than that of the OLC alone $\left(\sim 1.2 \Omega \mathrm{cm}^{2}\right)$, meaning that the ionic resistance within the porous structure of the pure EDLC (OLC alone) is increased for the OLC/ $\mathrm{MnO}_{2}$ pseudocapacitor. From the Bode plots, the phase angle for the pure OLC is $-85^{\circ}$ (which is close to the 


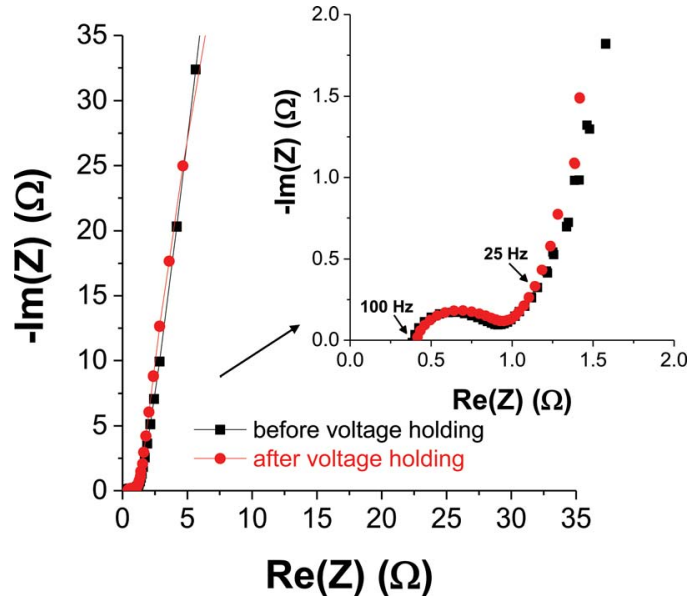

Fig. 8 Nyquist plot for the $\mathrm{OLC} / \mathrm{MnO}_{2}$ symmetric pseudocapacitor before and after $50 \mathrm{~h}$ voltage holding experiments. The inset is the expanded portion of the high frequency region. Electrolyte: aqueous $1 \mathrm{M} \mathrm{Na}_{2} \mathrm{SO}_{4}$.

$-90^{\circ}$ for an ideal EDLC) compared to the OLC $/ \mathrm{MnO}_{2}$ which is $-80^{\circ}$, further indicating the pseudocapacitive behavior of the $\mathrm{OLC} / \mathrm{MnO}_{2}$ device. The knee frequency $\left(f_{\mathrm{o}}, \phi=-45^{\circ}\right)$ describes the maximum frequency at which the capacitive behavior is dominant, and is a measure of the power capability of a supercapacitor; the higher the $f_{\mathrm{o}}$ the more rapidly the supercapacitor can be charged and discharged or the higher the power density that can be achieved from the supercapacitor. The values of $f_{\mathrm{o}}$ were $c a .25 \mathrm{~Hz}$ for the $\mathrm{OLC} / \mathrm{MnO}_{2}$ (time constant $\sim 40 \mathrm{~ms}$ ) and $5 \mathrm{~Hz}$ (time constant $\sim 0.2 \mathrm{~s}$ ) for the OLC, which further corroborates the higher power performance of the OLC/ $\mathrm{MnO}_{2}$ over its OLC counterpart. It is important to note that the $f_{\mathrm{o}}$ values remain approximately the same for both devices before and after $50 \mathrm{~h}$ voltage holding. This result shows that most of the stored energy in $\mathrm{OLC} / \mathrm{MnO}_{2}$ is accessible up to $25 \mathrm{~Hz}$, that is, the energy output available on the millisecond time scale. It should be stated here that most commercially available supercapacitors, including those designed for higher power applications, operate at frequencies less than $1 \mathrm{~Hz}^{62}$

\section{Conclusions}

This work investigated the electrochemical performance of highly graphitized onion-like carbon integrated with nanostructured birnessite-type $\mathrm{MnO}_{2}$ materials $\left(\mathrm{OLC} / \mathrm{MnO}_{2}\right)$ when used as a symmetrical pseudocapacitor device. From the halfcell experiment, the $\mathrm{OLC} / \mathrm{MnO}_{2}$ nanohybrid exhibited better performance when using $\mathrm{Ni}$ foam as the current collector (in terms of specific capacitance and rate capability) compared to a Pt disc substrate. Based on its excellent performance, Ni foam was used to fabricate the $\mathrm{OLC} / \mathrm{MnO}_{2}$ symmetric pseudocapacitor. The device gave excellent electrochemical performance with a specific capacity of $408 \mathrm{~F} \mathrm{~g}^{-1}$, specific energy density of $5.6 \mathrm{~W} \mathrm{~h} \mathrm{~kg}^{-1}$, power density of $74.8 \mathrm{~kW} \mathrm{~kg}^{-1}$, capacity retention upon long-hour voltage-holding and cycling, very low equivalent distributed resistance (EDR $\approx 3 \Omega \mathrm{cm}^{2}$ ), and very short RC time constant (40 ms). Using such a nanohybrid material, it is possible to overcome the main limitation of $\mathrm{MnO}_{2}$, namely its poor electrical conductivity $\left(10^{-6}\right.$ to $\left.10^{-5} \mathrm{~S} \mathrm{~cm}^{-1}\right)$ and to exploit its main advantages, namely low-cost, high abundance, and environmental friendliness, for high power energy storage devices. Indeed, the electrochemical properties of OLC/ $\mathrm{MnO}_{2}$ nanohybrids as high-rate energy storage devices have great potential for the development of high power aqueous-based supercapacitors that can be deployed for high-power technological applications.

\section{Acknowledgements}

This work was funded by the CSIR as well as the South Africa's Department of Science and Technology (DST) and National Research Foundation (NRF) under the "Nanotechnology Flagship Programme" (supercapacitors and fuel cell project, Grant no: 69849). KM thanks the DST/NRF for scarce skill doctoral scholarship. PME and KR thank the NRF for postdoctoral fellowships. CSIR, INM, and Saarland University are partners in the CREATe-Network funded by the European Commission. The INM is part of the Leibniz Research Alliance Energy Transition (LVE). The authors acknowledge the funding from the German Federal Ministry for Research and Education (BMBF) in support of the nanoEES ${ }^{3 \mathrm{D}}$ project (award number 03EK3013) as part of the strategic funding initiative energy storage framework. MZ and VP thank Prof. Eduard Arzt (INM) for his continuous support. Dipl.-Ing. Sebastian Slawik and Prof. Frank Mücklich (Chair of Functional Materials, Saarland University) are thanked for their support regarding X-ray diffraction.

\section{References}

1 F. Béguin, V. Presser, a. Balducci and E. Frackowiak, Adv. Mater., 2014, 2219.

2 A. Burke, J. Power Sources, 2000, 91, 37.

3 P. Simon, Y. Gogotsi and B. Dunn, Science, 2014, 343, 1210.

4 V. Augustyn, P. Simon and B. Dunn, Energy Environ. Sci., 2014, 7, 1597.

5 P. Simon and Y. Gogotsi, Nat. Mater., 2008, 7, 845.

6 Y. Zhai, Y. Dou, D. Zhao, P. F. Fulvio, R. T. Mayes and S. Dai, Adv. Mater., 2011, 23, 4828.

7 B. E. Conway, V. Birss and J. Wojtowicz, J. Power Sources, 1997, 66, 1.

8 R. Kotz and M. Carlen, Electrochim. Acta, 2000, 45, 2483.

9 E. Frackowiak and F. Béguin, Carbon, 2001, 39, 937.

10 J. R. Miller, Science, 2012, 335, 1312.

11 C. Largeot, C. Portet, J. Chmiola, P. Taberna, Y. Gogotsi and P. Simon, J. Am. Chem. Soc., 2008, 130, 2730.

12 E. Frackowiak, Phys. Chem. Chem. Phys., 2007, 9, 1774.

13 A. T. Chidembo, K. I. Ozoemena, B. O. Agboola, V. Gupta, G. G. Wildgoose and R. G. Compton, Energy Environ. Sci., 2010, 3, 228.

14 A. Bello, K. Makgopa, M. Fabiane, D. Dodoo-Ahrin, K. I. Ozoemena and N. Manyala, J. Mater. Sci., 2013, 48, 6707. 
15 C. J. Jafta, F. Nkosi, L. le Roux, M. K. Mathe, M. Kebede, K. Makgopa, Y. Song, D. Tong, M. Oyama, N. Manyala, S. Chen and K. I. Ozoemena, Electrochim. Acta, 2013, 2.

16 E. J. Ra, E. Raymundo-Piñero, Y. H. Lee and F. Béguin, Carbon, 2009, 47, 2984.

17 J. Li, E. Liu, W. Li, X. Meng and S. Tan, J. Alloys Compd., 2009, 478, 371.

18 U. Fischer, R. Saliger and V. Bock, J. Porous Mater., 1997, 285, 281.

19 Y. Wang, Z. J. Han, S. F. Yu, R. R. Song, H. H. Song, K. Ken Ostrikov and H. Y. Yang, Carbon, 2013, 64, 230.

20 Y. Wang, F. Yan, S. W. Liu, A. Y. S. Tan, H. Song, X. W. Sun and H. Y. Yang, J. Mater. Chem. A, 2013, 1, 5212.

21 D. M. Anjos, J. K. McDonough, E. Perre, G. M. Brown, S. H. Overbury, Y. Gogotsi and V. Presser, Nano Energy, 2013, 2, 702 .

22 I. Kovalenko, D. G. Bucknall and G. Yushin, Adv. Funct. Mater., 2010, 20, 3979.

23 Y. Gao, Y. S. Zhou, M. Qian, X. N. He, J. Redepenning, P. Goodman, H. M. Li, L. Jiang and Y. F. Lu, Carbon, 2013, 51, 52.

24 E. G. Bushueva, P. S. Galkin, A. V. Okotrub, L. G. Bulusheva, N. N. Gavrilov, V. L. Kuznetsov and S. I. Moiseekov, Phys. Status Solidi, 2008, 245, 2296.

25 C. Portet, G. Yushin and Y. Gogotsi, Carbon, 2007, 45, 2511.

26 J. K. McDonough, A. I. Frolov, V. Presser, J. Niu, C. H. Miller, T. Ubieto, M. V. Fedorov and Y. Gogotsi, Carbon, 2012, 50, 3298.

27 I. Suarez-Martinez, N. Grobert and C. P. Ewels, Carbon, 2012, 50, 741 .

28 V. N. Mochalin, O. Shenderova, D. Ho and Y. Gogotsi, Nat. Nanotechnol., 2012, 7, 11.

29 D. Pech, M. Brunet, H. Durou, P. Huang, V. Mochalin, Y. Gogotsi, P.-L. Taberna and P. Simon, Nat. Nanotechnol., 2010, 5, 651 .

30 M. V. K. Azhagan, M. V. Vaishampayan and M. V. Shelke, J. Mater. Chem. A, 2014, 2, 2152.

31 V. L. Kuznetsov, A. L. Chuvilin, Y. V. Butenko, I. Y. Mal'kov and V. M. Titov, Chem. Phys. Lett., 1994, 222, 343.

32 D. Urgate, Nature, 1992, 359, 707.

33 S. Iijima, J. Cryst. Growth, 1980, 50, 675.

34 M. Choucair and J. A. Stride, Carbon, 2012, 50, 1109.

35 C. Julien, Solid State Ionics, 2003, 159, 345.

36 C. Matei Ghimbeu, A. Malak-Polaczyk, E. Frackowiak and C. Vix-Guterl, J. Appl. Electrochem., 2013, 44, 123.

37 P. Yu, X. Zhang, Y. Chen and Y. Ma, Mater. Lett., 2010, 64, 1480.

38 B. Ming, J. Li, F. Kang, G. Pang, Y. Zhang, L. Chen, J. Xu and X. Wang, J. Power Sources, 2012, 198, 428.

39 M. Huang, Y. Zhang, F. Li, L. Zhang, R. S. Ruoff, Z. Wen and Q. Liu, Sci. Rep., 2014, 4, 3878.

40 X. Zhang, X. Sun, H. Zhang, D. Zhang and Y. Ma, Mater. Chem. Phys., 2012, 137, 290.

41 X. Zhang, P. Yu, H. Zhang, D. Zhang, X. Sun and Y. Ma, Electrochim. Acta, 2013, 89, 523.

42 Y. Wang, S. F. Yu, C. Y. Sun, T. J. Zhu and H. Y. Yang, J. Mater. Chem., 2012, 22, 17584.
43 P. Yang, Y. Ding, Z. Lin, Z. Chen, Y. Li, P. Qiang, M. Ebrahimi, W. Mai, C. P. Wong and Z. L. Wang, Nano Lett., 2014, 14, 731.

44 Z.-S. Wu, W. Ren, D.-W. Wang, F. Li, B. Liu and H.-M. Cheng, ACS Nano, 2010, 4, 5835.

45 H. Xia, Y. Wang, J. Lin and L. Lu, Nanoscale Res. Lett., 2012, $7,33$.

46 H. Yang, J. Jiang, W. Zhou, L. Lai, L. Xi, Y. M. Lam, Z. Shen,

B. Khezri and T. Yu, Nanoscale Res. Lett., 2011, 6, 531.

47 D. Weingarth, M. Zeiger, N. Jäckel, M. Aslan, G. Feng and

V. Presser, Adv. Energy Mater., 2014, 4, 1400316.

48 S. Brunauer, P. H. Emmett and E. Teller, J. Am. Chem. Soc., 1938, 60, 309.

49 G. Y. Gor, M. Thommes, K. A. Cychosz and A. V. Neimark, Carbon, 2012, 50, 1583.

50 Y. V. Butenko, V. L. Kuznetsov, A. L. Chuvilin, V. N. Kolomiichuk, S. V. Stankus, R. A. Khairulin and B. Segall, J. Appl. Phys., 2000, 88, 4380.

51 T. K. Gupta, B. P. Singh, V. N. Singh, S. Teotia, A. P. Singh, I. Elizabeth, S. R. Dhakate, S. K. Dhawan and R. B. Mathur, J. Mater. Chem. A, 2014, 2, 4256.

52 K. Bogdanov, A. Fedorov, V. Osipov, T. Enoki, K. Takai, T. Hayashi, V. Ermakov, S. Moshkalev and A. Baranov, Carbon, 2014, 73, 78.

53 D. Yang and M. Wang, Chem. Mater., 2001, 13, 2589.

54 F.-J. Liu, J. Power Sources, 2008, 182, 383.

55 Z. Li, Y. Mi, X. Liu, S. Liu, S. Yang and J. Wang, J. Mater. Chem., 2011, 21, 14706.

56 Y.-K. Hsu, Y.-C. Chen, Y.-G. Lin, L.-C. Chen and K.-H. Chen, J. Mater. Chem., 2012, 22, 2733.

57 M. C. Biesinger, B. P. Payne, A. P. Grosvenor, L. W. M. Lau, A. R. Gerson and R. S. C. Smart, Appl. Surf. Sci., 2011, 257, 2717.

58 T. E. Rufford, D. Hulicova-Jurcakova, K. Khosla, Z. Zhu and G. Q. Lu, J. Power Sources, 2010, 195, 912.

59 L.-Y. Lin, M.-H. Yeh, J.-T. Tsai, Y.-H. Huang, C.-L. Sun and K.-C. Ho, J. Mater. Chem. A, 2013, 1, 11237.

60 D. Weingarth, A. Foelske-Schmitz and R. Kötz, J. Power Sources, 2013, 225, 84.

61 P. Ratajczak, K. Jurewicz and F. Béguin, J. Appl. Electrochem., 2013, 44, 475.

62 J. R. Miller, Electrochem. Soc. Proc. Ser., 1996, 246, PV95-29. 63 Y. Zhao, P. Jiang and S.-S. Xie, J. Power Sources, 2013, 239, 393.

64 W. Li, Q. Liu, Y. Sun, J. Sun, R. Zou, G. Li, X. Hu, G. Song, G. Ma, J. Yang, Z. Chen and J. Hu, J. Mater. Chem., 2012, 22, 14864.

65 Y. Zhang, G. Li, Y. Lv, L. Wang, A. Zhang, Y. Song and B. Huang, Int. J. Hydrogen Energy, 2011, 36, 11760.

66 Y. Zhang, C. Sun, P. Lu, K. Li, S. Song and D. Xue, CrystEngComm, 2012, 14, 5892.

67 H. Jang, S. Suzuki and M. Miyayama, J. Electrochem. Soc., 2012, 159, A1425.

68 W. Ko, L. Chen, Y. Chen, W. Chen, K. Lu, J. Yang, Y. Yen and K. Lin, J. Phys. Chem. C, 2013, 117, 16290.

69 M. Kundu and L. Liu, J. Power Sources, 2013, 243, 676. 
70 J. Zhu, W. Shi, N. Xiao, X. Rui, H. Tan, X. Lu, H. H. Hng, J. Ma and Q. Yan, ACS Appl. Mater. Interfaces, 2012, 4, 2769.

71 L. Chen, N. Gu, R. Ding, L. Qi and H. Wang, J. Solid State Electrochem., 2013, 17, 2579.

72 H.-Q. Wang, G. Yang, Q.-Y. Li, X.-X. Zhong, F.-P. Wang, Z.-S. Li and Y. Li, New J. Chem., 2011, 35, 469.

73 Z. Yu, B. Duong, D. Abbitt and J. Thomas, Adv. Mater., 2013, 25, 3302 .
74 A. Bello, O. O. Fashedemi, J. N. Lekitima, M. Fabiane, D. Dodoo-Arhin, K. I. Ozoemena, Y. Gogotsi, A. T. Charlie Johnson and N. Manyala, AIP Adv., 2013, 3, 082118.

75 Q. Li, X.-F. Lu, H. Xu, Y.-X. Tong and G.-R. Li, ACS Appl. Mater. Interfaces, 2014, 6, 2726.

76 R. B. Rakhi, W. Chen, D. Cha and H. N. Alshareef, Adv. Energy Mater., 2012, 2, 381.

77 R. Borgohain, J. P. Selegue and Y.-T. Cheng, J. Mater. Chem. A, 2014, 2, 20367. 